Cite this: Dalton Trans., 2014, 43, 4587

Received 16th November 2013, Accepted 20th January 2014

DOI: $10.1039 / c 3 d t 53243 g$

www.rsc.org/dalton

\section{Narcissistic self-sorting vs. statistic ligand shuffling within a series of phenothiazine-based coordination cages $\uparrow$}

\author{
Marina Frank, Lennard Krause, Regine Herbst-Irmer, Dietmar Stalke and \\ Guido H. Clever*
}

\begin{abstract}
Previously, we introduced a series of anion-binding interpenetrated double-cages based on phenothiazine and its mono- and di-S-oxygenated derivatives. Here, we complete the structural comparison of the three related assemblies by an X-ray single crystal analysis of the sulfone derivative. We further show that the three palladium cages coexist in solution upon post-assembly mixing due to the very slow ligand exchange whereas treatment of binary mixtures of the corresponding ligands with Pd(॥) leads to the formation of mixed cages comprising a statistical ligand distribution. In contrast, mixtures of one of these ligands with a shorter ligand derivative lead to narcissistic self-assembly into a double-cage and a coexisting small monomeric cage, regardless of the order of mixing and $\mathrm{Pd}(॥)$ addition.
\end{abstract}

\section{Introduction}

Self-assembled coordination cages ${ }^{1}$ have found application in various areas such as selective guest binding, ${ }^{2}$ stabilisation of reactive compounds, ${ }^{3}$ catalysis, ${ }^{4}$ redoxactive ${ }^{5}$ and light switchable materials. ${ }^{6}$ We have recently reported on a number of interpenetrated double-cages $\left[\mathrm{Pd}_{4} \mathbf{L}_{8}\right]$ containing concave bismonodentate pyridyl ligands $\mathbf{L}$ showing an allosteric anion binding behaviour. ${ }^{7}$ We further showed that small structural changes modulate the binding affinity of these cages for different halide anions ${ }^{8}$ whereas more extensive structural changes lead to a selectivity switch towards larger oxoanions such as perrhenate. ${ }^{9}$

Among the reported structures, three closely related doublecage species based on the heterocycle phenothiazine and its mono- and di-oxygenated derivatives were shown to have a redox chemistry that makes them promising candidates for application in molecular electronics and organic photovoltaics. The molecular structures of the first two cages were reported by us before. ${ }^{10}$

Here, we deliver the single-crystal structure of the di-S-oxygenated double-cage, thus allowing for a comprehensive comparison of the structure-function relationships of the three cage derivatives. Furthermore, we extended our examination of

Institut für AnorganischeChemie, Georg-August Universität Göttingen, Tammannstr. 4, 37077 Göttingen, Germany.E-mail: gclever@gwdg.de $\dagger$ Electronic supplementary information (ESI) available. CCDC 972251. For ESI and crystallographic data in CIF or other electronic format see DOI: $10.1039 / \mathrm{c} 3 \mathrm{dt} 53243 \mathrm{~g}$ the cage assembly process to mixtures of phenothiazine-based ligands and their corresponding cages in order to study the role of kinetic effects ${ }^{11}$ on the double-cage assembly. In addition, we show a phenomenon of narcissistic self-sorting ${ }^{12}$ when a shorter ligand derivative, not capable of forming a double-cage, is brought into the system.

\section{Results and discussion}

The chemical structures of the long ligands $\mathbf{L}^{\mathbf{1 - 3}}$ and the shorter derivative $\mathbf{L}^{\mathbf{4}}$ are depicted in Fig. 1a. All three long ligands were previously shown to quantitatively yield interpenetrated double-cages $\left[\mathrm{Pd}_{4} \mathbf{L}_{8}^{1-3}\right]$ upon treatment with the metal source $\left[\mathrm{Pd}-\left(\mathrm{CH}_{3} \mathrm{CN}\right)_{4}\right]\left(\mathrm{BF}_{4}\right)_{2}$ in acetonitrile solution. ${ }^{10}$ The structures were found to contain $\mathrm{BF}_{4}{ }^{-}$counter anions encapsulated in their two outer pockets and one inside their central cavity. We further showed that the two outer anions could be replaced by tightly binding halides in an allosteric fashion. ${ }^{8}$ In contrast, the shorter ligand $\mathbf{L}^{\mathbf{4}}$ was shown to assemble into a monomeric cage $\left[\operatorname{Pd}_{2} \mathbf{L}_{4}{ }_{4}\right]$ that cannot undergo dimerization for steric reasons. ${ }^{10}$

The X-ray structural data for coordination cages $\left[\operatorname{Pd}_{4} \mathbf{L}_{8}{ }_{8}\right]$ and $\left[\mathrm{Pd}_{4} \mathbf{L}_{8}^{2}\right]$ showed that both are interpenetrated dimers sharing a common topology but differing in their shape with regard to the $\mathrm{Pd}-\mathrm{Pd}$ distances, ligand bending and pocket sizes. ${ }^{10}$ Here, we report on the single crystal X-ray structure of the third member of the three related cages, $\left[\operatorname{Pd}_{4} \mathbf{L}_{8}{ }_{8}\right]$, thus filling a gap in the systematic structural comparison. Table 1 lists the crystallographic parameters for the $\left[\mathrm{Pd}_{4} \mathbf{L}^{3}{ }_{8}\right]$ double 
a)
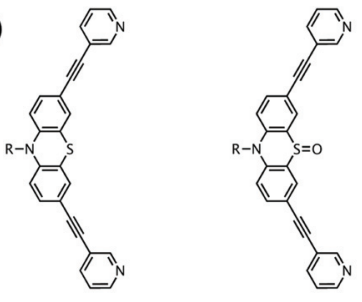

$\mathbf{L}^{1}$

$d(\mathrm{~N}, \mathrm{~N}) \quad 17.616$
$\mathbf{L}^{2}$
16.786
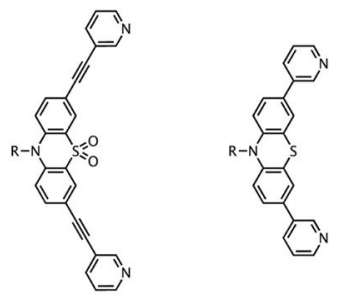

$\mathrm{L}^{3}$
$\mathbf{L}^{4}$

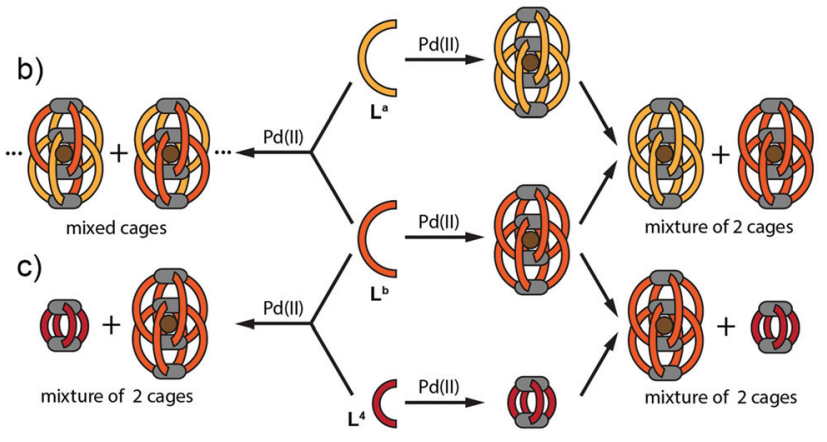

Fig. 1 (a) Chemical structures of the cage-forming ligands $L^{1-4}$. The given $\mathrm{N}, \mathrm{N}$-distances are based on double-cage $\mathrm{X}$-ray structures for $\mathrm{L}^{1-3}$ and a semiempirical PM6 model for the monomeric cage based on ligand $\mathrm{L}^{4}$. (b) For binary systems containing two different long ligands $L^{a}+L^{b}\left(L^{a}, L^{b}=L^{1-3} ; L^{a} \neq L^{b}\right)$ the outcome of the self-assembly gives mixed cages showing a statistical ligand distribution when the ligands are mixed prior to the addition of palladium. In contrast, combining two preassembled double-cages $\left[\mathrm{Pd}_{4} \mathrm{~L}_{8}{ }_{8}\right]+\left[\mathrm{Pd}_{4} \mathrm{~L}_{8}^{\mathrm{b}}\right]$ leads to a mixture of coexisting homogeneous structures between which ligand exchange is tremendously slowed down. (c) For binary systems containing one long ligand $\left(\mathrm{L}^{\mathrm{b}}=\mathrm{L}^{1-3}\right)$ and the short ligand $\mathrm{L}^{4}$, the outcome of the selfassembly is independent of the order of mixing of the components. In both cases, this system shows narcissistic self-sorting behaviour to give $\left[\mathrm{Pd}_{4} \mathrm{~L}_{8}^{\mathrm{b}}\right]+\left[\mathrm{Pd}_{2} \mathrm{~L}_{4}^{4}\right]$.

Table 1 Crystallographic data for $\left[\mathrm{Pd}_{4} \mathrm{~L}_{8}^{3}\right]$

CCDC number

Empirical formula

Formula weight

Temperature

Wavelength

Crystal system

Space group

Unit cell dimensions

Volume

Z

Density (calculated)

Absorption coeff.

$F(000)$

Crystal size

Theta range for data collection

Index ranges

Reflections collected

Independent refl.

Refinement method

Data/restraints/parameters

Goodness-of-fit on F2

Final $R$ indices $[I>2 \sigma(I)]$

$R$ indices (all data)

Largest diff. peak and hole
972251

$\mathrm{C}_{512} \mathrm{H}_{432} \mathrm{~B}_{14} \mathrm{Cl}_{2} \mathrm{~F}_{56} \mathrm{~N}_{48} \mathrm{O}_{32} \mathrm{Pd}_{8} \mathrm{~S}_{16}$ $8 \times 1302.43 \mathrm{~g} \mathrm{~mol}^{-1}$

$100(2) \mathrm{K}$

$0.71073 \AA$

Tetragonal

P4/nnc

$a=b=21.991(2) \AA$

$c=31.800(3) \AA$

$15378(2) \AA^{3}$

8

$1.125 \mathrm{Mg} \mathrm{m}^{-3}$

$0.363 \mathrm{~mm}^{-1}$

5328

$0.09 \times 0.08 \times 0.06 \mathrm{~mm}^{3}$

1.126 to $23.837^{\circ}$.

$-25 \leq h \leq 24,-24 \leq k \leq 24$,

$-36 \leq l \leq 36$

166252

$5937\left[R_{\text {int }}=0.0583\right]$

Full-matrix least-squares on $F^{2}$ $5937 / 1104 / 682$

1.058

$R_{1}=0.0797, \mathrm{w} R_{2}=0.2565$

$R_{1}=0.1049, \mathrm{w} R_{2}=0.3011$

1.429 and $-0.662 \mathrm{e}^{-3}$ cage. After refinement of the cage scaffold, all necessary $\mathrm{BF}_{4}{ }^{-}$ and $\mathrm{Cl}^{-}$anions could be found in the Fourier difference map. The $\mathrm{BF}_{4}{ }^{-}$anions are located on special positions. All but one are exhibiting disorder and are not obeying the crystallographic symmetry. They were modeled using distance restraints with lowered standard deviations. Diffuse residual electron density was observed in the crystal voids. Heavily disordered lattice solvent (ethanol) could be modeled into these voids but a 'squeezed' model was superior. (see the ESI $\dagger$ ).

Fig. $2 \mathrm{a}$ and $\mathrm{b}$ show the double cage structure from two different perspectives. The topology of this cage assembly is in

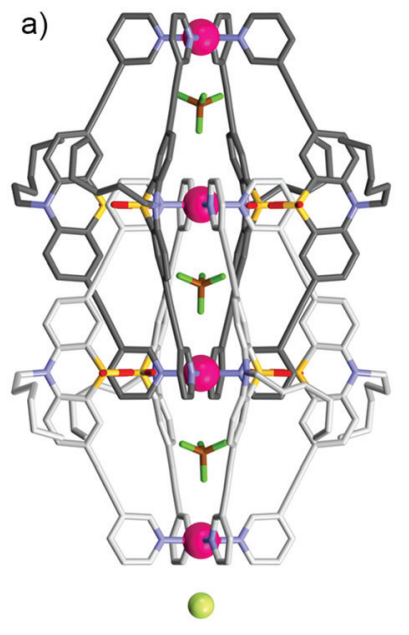

b)
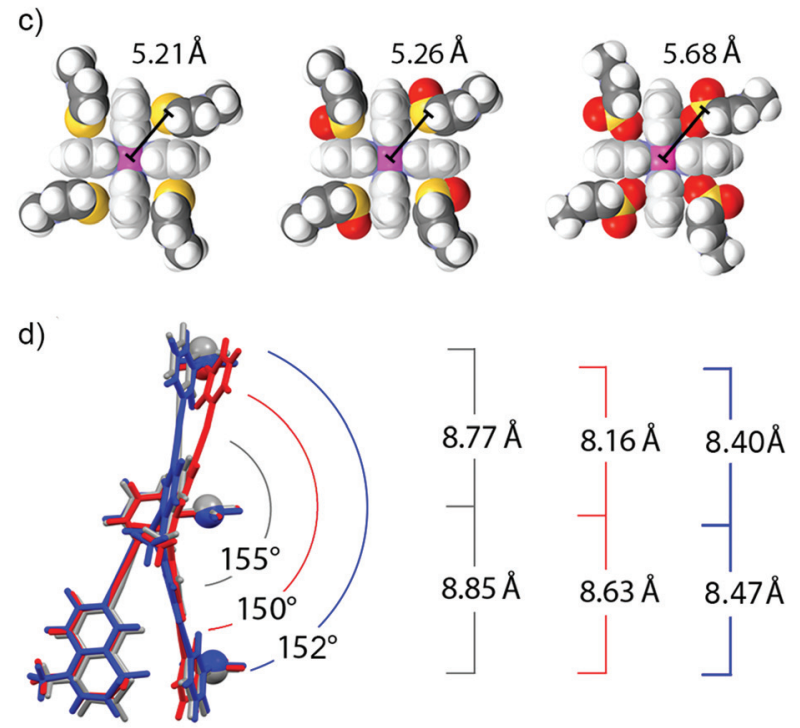

Fig. 2 (a) Side view and (b) view along the $\mathrm{Pd}_{4}$-axis of the single crystal $X$-ray structure of the interpenetrated double-cage $\left[\mathrm{Pd}_{4} \mathrm{~L}_{8}^{3}\right]$ (only the three internal $\mathrm{BF}_{4}{ }^{-}$and the two external $\mathrm{Cl}^{-}$anions are depicted. Other anions and solvent molecules are omitted for clarity. C: grey, $\mathrm{N}$ : blue, $\mathrm{O}$ : red, S: yellow, B: brown, F: dark green, Cl: light green, Pd: purple). (c) Comparison of the space-filling top views of one of the inner Pd(pyridine) ${ }_{4}$ planes of double-cages $\left[\mathrm{Pd}_{4} \mathrm{~L}_{8}{ }_{8}\right]$ (left), $\left[\mathrm{Pd}_{4} \mathrm{~L}^{2}{ }_{8}\right]$ (middle) and $\left[\mathrm{Pd}_{4} \mathrm{~L}_{8}^{3}\right]$ (right). (d) Partial overlay of sub-structures of $\left[\mathrm{Pd}_{4} \mathrm{~L}_{8}^{1}\right]$ (grey), $\left[\mathrm{Pd}_{4} \mathrm{~L}^{2}{ }_{8}\right]$ (red) and $\left[\mathrm{Pd}_{4} \mathrm{~L}_{8}^{3}\right]$ (blue) indicating the changes in the ligand structures and $\mathrm{Pd}-\mathrm{Pd}$ distances. 
agreement with the structures reported for $\left[\operatorname{Pd}_{4} \mathbf{L}_{8}{ }_{8}\right]$ and $\left[\operatorname{Pd}_{4} \mathbf{L}_{3}^{2}\right]$. It is interesting to note that the examined crystals of $\left[\mathrm{Pd}_{4} \mathbf{L}_{8}^{3}\right]$ were found to contain one equivalent of chloride counter anions per double-cage, positioned on the $\mathrm{Pd}_{n}$-axis between the double-cages, which was not observed in the previously reported solid states structures of $\left[\operatorname{Pd}_{4} \mathbf{L}_{8}{ }_{8}\right]$ and $\left[\mathrm{Pd}_{4} \mathbf{L}^{2}{ }_{8}\right]$. Particularly surprising is the observation that the chloride anions (most probably being the result of a contamination) were not found in the outer two pockets of the doublecage structure but in the space outside the linearly aligned cages, which is in clear contrast to the solution behaviour. ${ }^{8}$ A plausible explanation is given as follows: in solution, the chloride anions are tightly bound inside the outer two pockets by electrostatic interactions from both $\mathrm{Pd}(\text { pyridine })_{4}$ planes lining the cavities. As we have demonstrated previously, ${ }^{7,8}$ chloride binding is accompanied by a compression of the double cage structure along the $\mathrm{Pd}_{4}$-axis thus bringing the Pd centres of the outer pockets closer together. This allosteric effect helps to accommodate the chloride anions in the outer pockets because they are smaller than the tetrafluoroborate counter anions. As a consequence of this structural change, however, an energetic penalty has to be paid due to the enlargement of the central pocket because here the cationic metal centres are moved away from the contained tetrafluoroborate anion. Still, the incorporation of the chloride inside the outer pockets is the favoured process in solution, whereas chloride binding to the outer faces of the double cage is occurring with much lower affinity. The situation seems to change in the solid state structure due to the linear alignment of the double cages. Here, the cages can adopt an optimal spacing for the tight binding of a chloride anion between them (6.54 $\AA$ ). Most importantly, binding of the chloride anion between the cages does not come with the mentioned energetic drawback of having to enlarge the cage's central cavity. For a graphical comparison of the solid state packings of the three cage derivatives see the ESI. $\dagger$

A comparison of all three X-ray structures reveals how the sulfur atoms (and the attached oxygen atoms) of the interpenetrating ligands of one cage subunit are positioned relative to the inner $\operatorname{Pd}(\text { pyridine })_{4}$-plane of the other cage subunit (Fig. 2c). Compared to the situation observed for $\left[\operatorname{Pd}_{4} \mathbf{L}^{\mathbf{1}}{ }_{8}\right]$ (left) and $\left[\operatorname{Pd}_{4} \mathbf{L}^{2}{ }_{8}\right]$ (middle), the extra oxygen of $\left[\mathrm{Pd}_{4} \mathbf{L}_{8}^{3}\right]$ (right) has to squeeze between the sulfur atom and the gap between two neighbouring pyridine rings, which moves the sulfur atom further away from the palladium centre. A further structural feature, which is interesting to compare between the three cage derivatives, is the ligand bending (as defined by the angle between both of the phenothiazines' benzene rings). Fig. 2d shows that the attachment of one oxygen substituent to the sulfur decreases the bending angle from $155^{\circ}$ (in $\left[\operatorname{Pd}_{4} \mathbf{L}^{\mathbf{1}}{ }_{8}\right]$ ) to $150^{\circ}$ (in $\left[\mathrm{Pd}_{4} \mathbf{L}^{2}{ }_{8}\right]$ ) and back to $152^{\circ}\left(\right.$ in $\left.\left[\operatorname{Pd}_{4} \mathbf{L}_{8}^{3}\right]\right)$ which can be explained by the steric demands of the lone pairs and oxygen substituents, respectively.

Since no single crystals suitable for X-ray crystallography were obtained for the monomeric cage $\left[\operatorname{Pd}_{2} \mathbf{L}_{4}^{4}\right]$, its structure was calculated by an unconstrained geometry optimization on the PM6 semiempirical level of theory (charge: +4 ; spin- a)

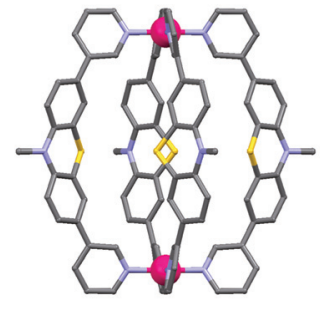

b)

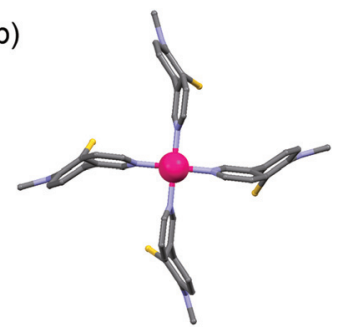

Fig. 3 (a) Side view and (b) view along the $\mathrm{Pd}_{2}$-axis of a PM6 model of the monomeric cage $\left[\mathrm{Pd}_{2} \mathrm{~L}_{4}^{4}\right.$ ] (alkyl chains have been truncated and anions omitted).

multiplicity: 1) in Gaussian 09. ${ }^{13}$ Fig. 3 shows the resulting optimized structure.

Having all three structures in hand, we next turned our focus to the examination of mixtures of the ligands and their corresponding cages. When two of the long ligands (named $\mathbf{L}^{\mathbf{a}}$ and $\mathbf{L}^{\mathbf{b}}$ in Fig. 1 with $\mathbf{L}^{\mathbf{a}}, \mathbf{L}^{\mathbf{b}}=\mathbf{L}^{\mathbf{1 - 3}} ; \mathbf{L}^{\mathbf{a}} \neq \mathbf{L}^{\mathbf{b}}$ ) were mixed in equimolar ratio, a stoichiometric amount of $\operatorname{Pd}(\mathrm{II})$ cations added and the mixture heated to $70{ }^{\circ} \mathrm{C}$ overnight, a statistical mixture of interpenetrated double-cages $\left[\operatorname{Pd}_{4} \mathbf{L}_{m}^{\mathbf{a}} \mathbf{L}^{\mathbf{b}}{ }_{8-m}\right](m=0-8)$ was obtained containing both ligands according to a binomial distribution. In contrast, when both cages $\left[\mathrm{Pd}_{4} \mathbf{L}_{8}^{\mathbf{a}}\right]$ and $\left[\operatorname{Pd}_{4} \mathbf{L}_{8}^{\mathbf{b}}\right]$ were preformed in separate vessels and combined subsequently, the reassembly into mixed-ligand cages was found to be extremely slow.

Fig. 4a shows the ${ }^{1} \mathrm{H}$ NMR spectroscopic results of this experiment for ligands $\mathbf{L}^{1}$ and $\mathbf{L}^{3}$. The signals of both ligands

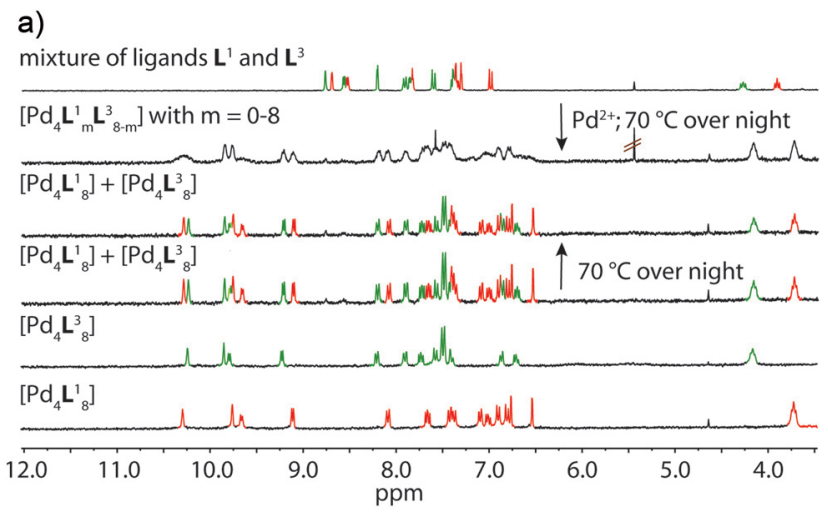

b)

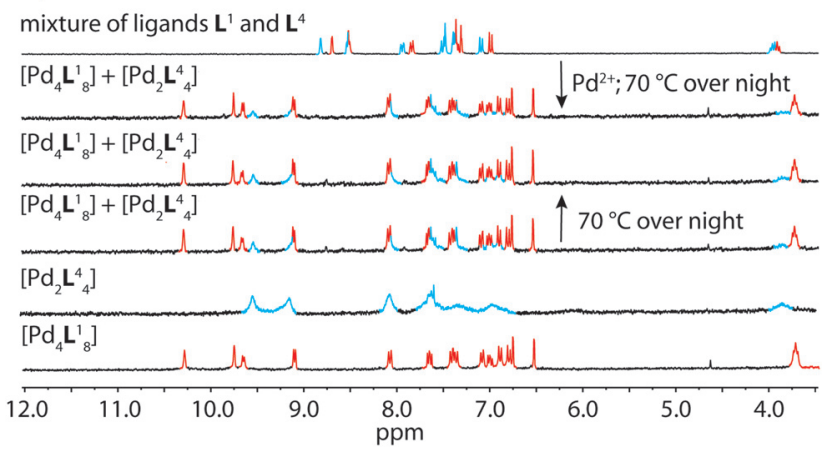

Fig. 4 Comparison of ${ }^{1} \mathrm{H}$ NMR spectra $\left(300 \mathrm{MHz}, 298 \mathrm{~K}, \mathrm{CD}_{3} \mathrm{CN}\right)$ of the experiments described in Fig. 1 with a combination of (a) ligands $L^{1}+L^{3}$ and (b) ligands $L^{1}+L^{4}$. 
(and corresponding double cages) are clearly distinguishable. The spectrum obtained after $\mathrm{Pd}(\mathrm{II})$ treatment of the ligand mixture unambiguously shows the pattern expected for an interpenetrated double-cage; it is however broadened as compared to the spectrum obtained for the mixture of the preformed cages.

The latter spectrum does not undergo substantial changes upon prolonged heating of the sample. The ESI mass spectrometric analysis of both mixtures nicely reveals that $\operatorname{Pd}(\mathrm{II})$ addition after ligand mixing indeed leads to a binomial distribution (Fig. 5a) whereas mixing of the preformed double-cages does not (Fig. 5b). Apart from some peaks resulting from contaminating counter anions, the observed peak pattern of this sample is in very good agreement with the simulated pattern for a 1:1 mixture of $\left[\operatorname{Pd}_{4} \mathbf{L}_{8}{ }_{8}\right]+\left[\operatorname{Pd}_{4} \mathbf{L}_{8}{ }_{8}\right]$.
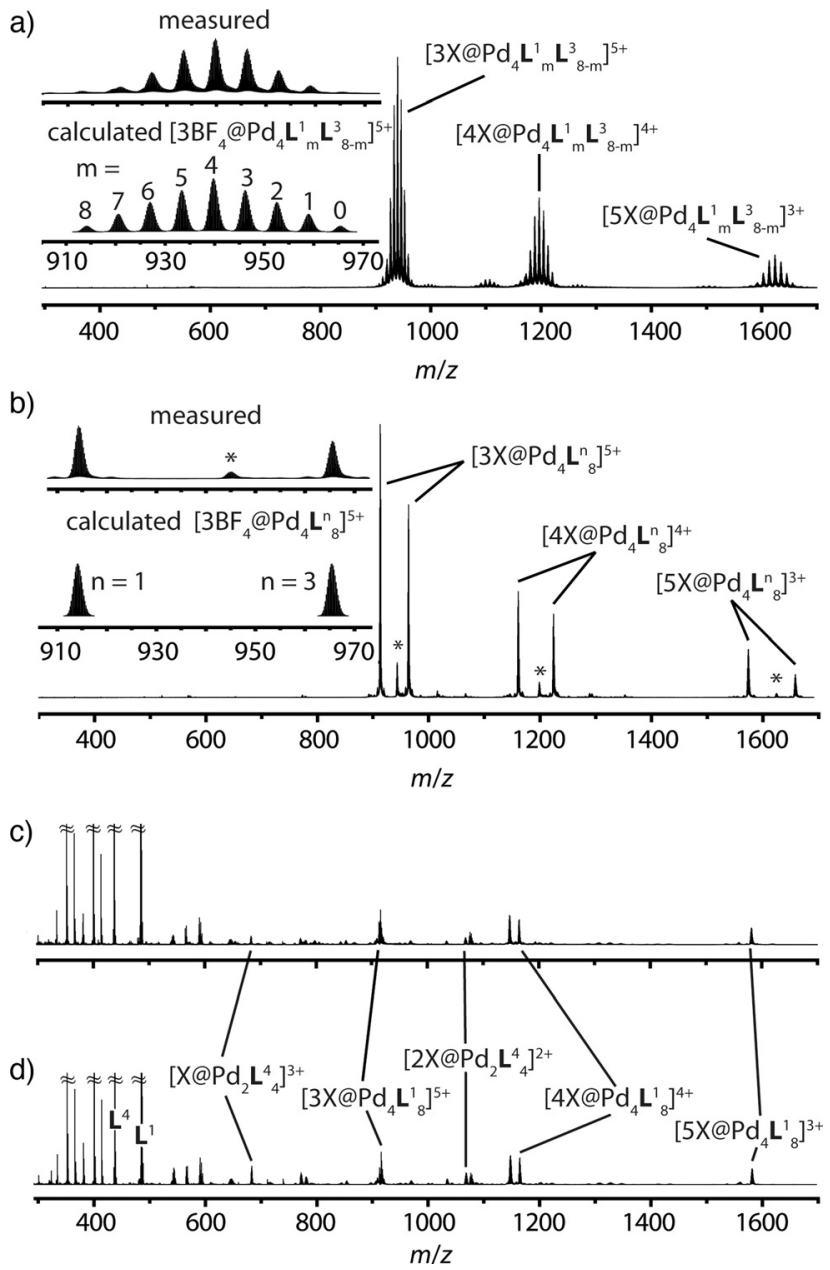

Fig. 5 Comparison of ESI-TOF mass spectra (positive mode, $\mathrm{CH}_{3} \mathrm{CN}$ ) of the experiments described in Fig. 1 showing (a) a statistical double-cage composition for the mixture of ligands $\mathrm{L}^{1}+\mathrm{L}^{3}$ and subsequent $\mathrm{Pd}(\|)$ addition and (b) non-exchanging species $\left[\mathrm{Pd}_{4} \mathrm{~L}_{8}^{1}\right]+\left[\mathrm{Pd}_{4} \mathrm{~L}_{8}{ }_{8}\right]$ for the mixture of preassembled double-cages ( ${ }^{*}$ corresponding double-cages containing other anions as contaminants; $\mathrm{X}=\mathrm{BF}_{4}{ }^{-}$and/or other small anions). In contrast, the system $L^{1}+L^{4}$ delivers essentially superimposable spectra showing a mixture of non-exchanging cages $\left[\mathrm{Pd}_{4} \mathrm{~L}_{8}{ }_{8}\right]+$ $\left[\mathrm{Pd}_{2} \mathrm{~L}_{4}^{4}\right]$, both (c) for the mixture of ligands $\mathrm{L}^{1}+\mathrm{L}^{4}$ and subsequent $\mathrm{Pd}(\mathrm{II})$ addition and (d) for the mixture of preassembled cages.
Heating the double-cage mixture at $70{ }^{\circ} \mathrm{C}$ overnight did not result in significant formation of mixed-ligand cages. ${ }^{11 a}$ Prolonged heating, however, led to the slow occurrence of new peaks with low intensity in the ESI mass spectra showing the formation of the one-ligand-exchanged species $\left[\operatorname{Pd}_{4} \mathbf{L}_{7}^{\mathbf{a}} \mathbf{L}_{1}^{\mathbf{b}}\right]$ and $\left[\operatorname{Pd}_{4} \mathbf{L}_{1}^{\mathbf{a}} \mathbf{L}_{7}^{\mathbf{b}}\right]$ after 279 hours (Fig. 6). Even further heating for up to 26 days led to the rise of the species where more than one ligand is exchanged, thus indicating a very slow ligand exchange. In addition the intensity of the signals for the homogeneous double cages $\left[\operatorname{Pd}_{4} \mathbf{L}_{8}{ }_{8}\right]$ and $\left[\operatorname{Pd}_{4} \mathbf{L}_{8}{ }_{8}\right]$ were found to decrease after this time. Since the same procedure conducted with the mixed-ligand double-cage samples did not result in any significant deviation from the statistical distribution, we conclude that the latter state is the global thermodynamic minimum of the system.

Similar results were obtained for mixtures containing $\mathbf{L}^{\mathbf{1}}+\mathbf{L}^{\mathbf{2}}$ and $\mathbf{L}^{2}+\mathbf{L}^{3}$, although the NMR spectroscopic analyses involving ligand $\mathbf{L}^{2}$ were somewhat hampered by the previously reported signal broadening in the spectra of $\left[\mathrm{Pd}_{4} \mathbf{L}_{8}{ }_{8}\right]$ (see the ESI $\dagger$ ). ${ }^{10}$

The picture changes when the short ligand $\mathbf{L}^{4}$ is brought into the system. Experiments involving one of the long ligands

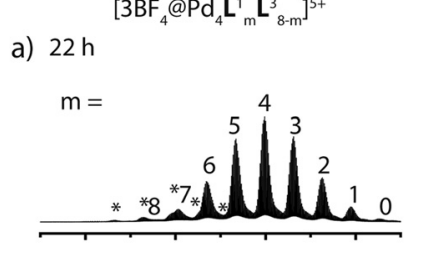

$\left[3 \mathrm{BF}_{4} @ \mathrm{Pd}_{4} \mathrm{~L}_{8}^{1}\right]^{5+}+\left[3 \mathrm{BF}_{4} @ \mathrm{Pd}_{4} \mathrm{~L}_{8}^{3}\right]^{5+}$

b) $114 \mathrm{~h}$
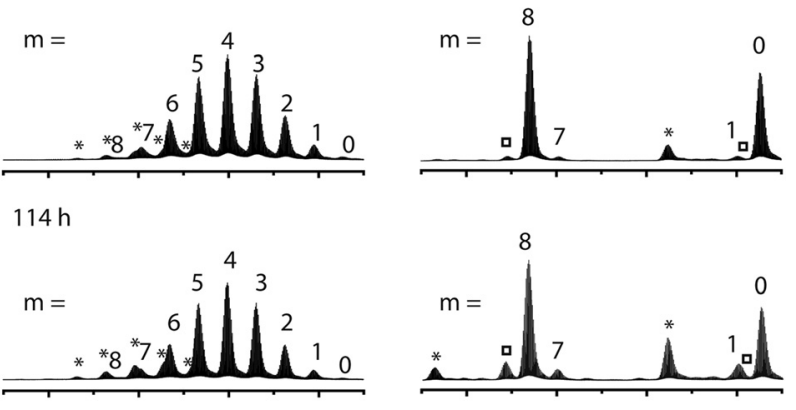

c) $279 \mathrm{~h}$
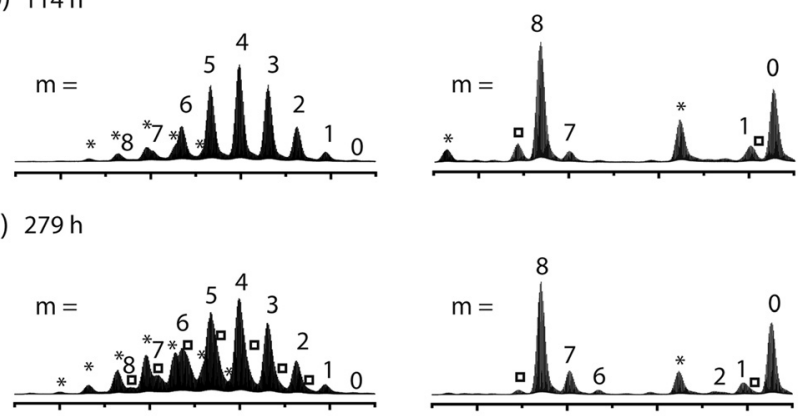

d) $615 \mathrm{~h}$
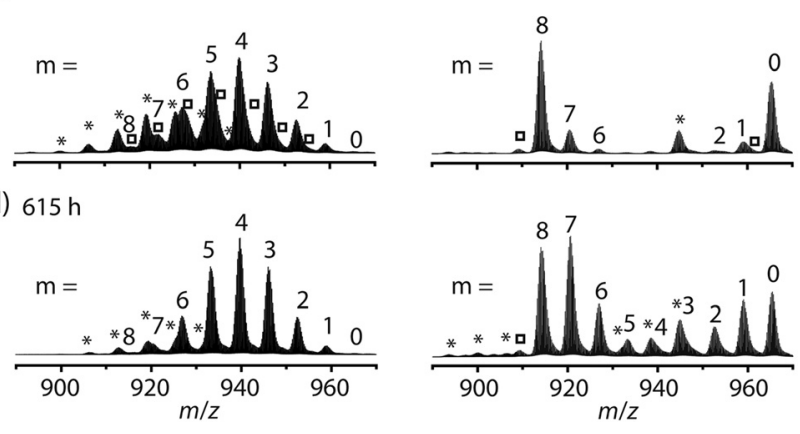

Fig. 6 (Left) ESI-TOF mass spectra in positive mode of the solution of premixed ligands $L^{1}$ and $L^{3}$ ( $250 \mu L$ of a $2.8 \mathrm{mM}$ solution for each ligand) after addition of 0.5 eq. $\left[\mathrm{Pd}\left(\mathrm{CH}_{3} \mathrm{CN}\right)_{4}\right]\left(\mathrm{BF}_{4}\right)_{2}$ and heating in $\mathrm{CD}_{3} \mathrm{CN}$ at $70{ }^{\circ} \mathrm{C}$. The spectra show that the statistical distribution of the ligands forming the double-cages $\left[\mathrm{Pd}_{4} \mathrm{~L}^{1}{ }_{m} \mathrm{~L}^{3}{ }_{8-m}\right]$ with $m=8-0$ is not changing over time. (Right) The ESI-TOF mass spectra in positive mode of the solution after mixing the double cages $\left[\mathrm{Pd}_{4} \mathrm{~L}^{1}{ }_{8}\right]$ and $\left[\mathrm{Pd}_{4} \mathrm{~L}^{3}{ }_{8}\right](250 \mu \mathrm{L}$ of a $0.35 \mathrm{mM}$ solution for each cage) and heating at $70{ }^{\circ} \mathrm{C}$ indicate a very slow, progressive ligand exchange process. Reaction times: (a) $22 \mathrm{~h}$, (b) $114 \mathrm{~h}$ and (c) $279 \mathrm{~h}$ and (d) $615 \mathrm{~h}$. *Denotes anion combinations with $2 \mathrm{Cl}^{-}+\mathrm{BF}_{4}^{-} ; \square$ denotes anion combinations with $\mathrm{NO}_{3}^{-}+2 \mathrm{BF}_{4}^{-}$. 
$\mathbf{L}^{1-3}$ plus $\mathbf{L}^{\mathbf{4}}$ were found to always result in a mixture of the homogeneous double-cage $\left[\mathrm{Pd}_{4} \mathbf{L}_{8}^{1-3}\right]$ and the small, monomeric cage $\left[\operatorname{Pd}_{2} \mathbf{L}_{4}{ }_{4}\right]$, regardless of the order of component addition (premixing of the ligands followed by $\operatorname{Pd(II)~vs.~}$ mixing of preassembled cages). This narcissistic self-sorting behaviour can be both seen in the ${ }^{1} \mathrm{H}$ NMR spectroscopic examinations (Fig. 4b) and the ESI mass spectrometric analyses (Fig. 5c and d) for the combination $\mathbf{L}^{\mathbf{1}}+\mathbf{L}^{\mathbf{4}}$ (for results of the other ligand combinations see the ESI $\dagger$ ).

\section{Conclusions}

In summary, the successful X-ray structure determination of $\left[\mathrm{Pd}_{4} \mathbf{L}_{8}{ }_{8}\right]$ allows now for a systematic comparison between all three members of the family of interpenetrated cages based on phenothiazine. The effect of the extra oxygen substituent attached to each of the eight sulfur atoms in $\left[\mathrm{Pd}_{4} \mathbf{L}_{8}{ }_{8}\right]$ has essentially two structural implications: first, it leads to a displacement of the sulfur atoms of the interpenetrating ligands away from the inner Pd atom of the other cage substructure, and second, it influences the bending angle of the ligands with respect to the non-flat phenothiazine component. Both factors also have implications on the pocket sizes (Pd-Pd distances) and overall double-cage shapes.

We further showed that binary mixtures of the long ligands $\mathbf{L}^{\mathbf{1}-\mathbf{3}}$ give a statistical distribution of mixed-ligand cages upon treatment with $\mathrm{Pd}(\mathrm{II})$. This is remarkable given the fact that all three ligands differ in their lengths, bending angle and steric situation around the sulfur atoms. Apparently, these discrepancies between the ligands are tolerated in the mixed cages, showing again the versatility of the $\left[\mathrm{Pd}_{4} \mathbf{L}_{8}\right]$ structural motif. Heating a mixture of preassembled double-cages, however, only resulted in extremely slow ligand shuffling, thus indicating a strong kinetic barrier of ligand exchange once the completely assembled double-cages have been obtained. The substantial structural differences between the long ligands $\mathbf{L}^{\mathbf{1 - 3}}$ and the much shorter derivative $\mathbf{L}^{\mathbf{4}}$, however, led to a narcissistic self-sorting behaviour in binary mixtures giving the corresponding double-cage $\left[\mathrm{Pd}_{4} \mathbf{L}_{8}^{1-3}\right]$ and the monomeric cage $\left[\operatorname{Pd}_{2} \mathbf{L}_{4}^{4}\right]$.

Together, these results strengthen the knowledge about the structural features that govern the formation of self-assembled coordination cages from concave bispyridyl ligands. Furthermore, the observed signs of a strong kinetic influence on the double-cage assembly mechanism allow us to study selfassembled host-guest systems away from thermodynamic equilibrium in our following investigations.

\section{Experimental}

${ }^{1} \mathrm{H}$ NMR spectra were recorded on a Bruker Avance-300 spectrometer $(300 \mathrm{MHz})$ in $\mathrm{CD}_{3} \mathrm{CN}$. ESI mass spectra were obtained using a Bruker micrOTOF mass spectrometer in positive mode. Samples were injected as acetonitrile solutions. All observed isotope patterns were in good agreement with the calculated ones.

Synthesis of the cages ${ }^{10}$ and preparation of the solutions for the mixing experiments: cage compounds $\left[\mathrm{Pd}_{4} \mathbf{L}_{8}^{1-3}\right]$ and $\left[\mathrm{Pd}_{2} \mathbf{L}_{4}{ }_{4}\right]$ were synthesized in quantitative yield by heating a mixture of the ligand $\mathbf{L}^{1-4}(2.8 \mu \mathrm{mol})$ in $930 \mu \mathrm{L} \mathrm{CD}_{3} \mathrm{CN}$ and a solution of $\left[\mathrm{Pd}\left(\mathrm{CH}_{3} \mathrm{CN}\right)_{4}\right]\left(\mathrm{BF}_{4}\right)_{2}(1.4 \mu \mathrm{mol}, 93 \mu \mathrm{L}$ of a $15 \mathrm{mM}$ solution in $\mathrm{CD}_{3} \mathrm{CN}$ ) at $70{ }^{\circ} \mathrm{C}$ for $6 \mathrm{~h}$ to give a $0.35 \mathrm{mM}$ solution of $\left[\mathrm{Pd}_{4} \mathbf{L}^{1-3}{ }_{8}\right]$ or a $0.7 \mathrm{mM}$ solution of $\left[\mathrm{Pd}_{2} \mathbf{L}_{4}{ }_{4}\right]$, respectively. Mixing experiments (Fig. 1b, left side): A binary solution of two ligands was prepared by mixing the solution of ligand $\mathbf{L}^{\mathbf{a}}$ $(250 \mu \mathrm{L}, 2.8 \mathrm{mM})$ and $\mathbf{L}^{\mathbf{b}}(250 \mu \mathrm{L}, 2.8 \mathrm{mM})$ in $\mathrm{CD}_{3} \mathrm{CN}$. To this solution, $\left[\mathrm{Pd}\left(\mathrm{CH}_{3} \mathrm{CN}\right)_{4}\right]\left(\mathrm{BF}_{4}\right)_{2}(0.75 \mu \mathrm{mol}, 50 \mu \mathrm{L}$ of a $15 \mathrm{mM}$ solution in $\mathrm{CD}_{3} \mathrm{CN}$ ) was added and the mixture was heated at $70{ }^{\circ} \mathrm{C}$ to give $\left[\operatorname{Pd}_{4} \mathbf{L}_{m}^{\mathbf{a}} \mathbf{L}^{\mathbf{b}}{ }_{8-m}\right]$ with $\mathbf{L}^{\mathbf{a}}, \mathbf{L}^{\mathbf{b}}=\mathbf{L}^{\mathbf{1 - 3}} ; \mathbf{L}^{\mathbf{a}} \neq \mathbf{L}^{\mathbf{b}} ;$ and $m=1-8$.

Mixing experiment (Fig. 1b, right side): A binary solution of preassembled double cages was prepared in $\mathrm{CD}_{3} \mathrm{CN}$ by mixing $250 \mu \mathrm{L}$ of each cage solution and heated at $70{ }^{\circ} \mathrm{C}$.

$\mathrm{X}$-ray crystallography: Yellow block shaped crystals of $\left[\mathrm{Pd}_{4} \mathbf{L}_{8}^{3}\right]$ were grown from the solution of the acetonitrile by diffusion of ethanol. A suitable crystal of size $0.09 \times 0.08 \times$ $0.06 \mathrm{~mm}^{3}$ was selected from a batch of crystals using the X-TEMP 2 device. ${ }^{14}$ The crystal was mounted on top of glass fiber using inert perfluorinated polyether oil and placed in the cold gas stream of a Bruker Kryoflex 2 low-temperature device with a cold stream at 100(2) K on a Bruker D8 three circle diffractometer. The diffractometer was equipped with a SMART APEX II CCD detector and a rotating anode source (Mo-K $\alpha ; \lambda=$ $0.71073 \AA$ ). Data were collected in omega-scan mode at different detector $2 \theta$ angles ranging between $0^{\circ}$ and $90^{\circ}$. The scan width was set to $0.5^{\circ}$.

Data integration was done with SAINT 8.30C. ${ }^{15}$ Each run with constant $2 \theta$ and $\varphi$ settings was integrated using a separate orientation matrix. Data scaling and absorption correction were done with SADABS 2012/1. ${ }^{16}$ The space group was determined using XPREP. ${ }^{17}$ The structure was solved by direct methods using SHELXS-97. ${ }^{18}$ Refinement by full-matrix leastsquares procedures was done with SHELXL-2013 ${ }^{19}$ within the SHELXLe-GUI. ${ }^{20}$ The hydrogen atoms were refined isotropically at calculated positions using a riding model with their $U_{\text {iso }}$ values constrained to $1.5 U_{\text {eq }}$ of their pivot atoms for terminal $\mathrm{sp}^{3}$ carbon atoms and 1.2 times for all other carbon atoms. All non-hydrogen atoms were refined with anisotropic displacement parameters. For the severely disordered solvent region the SQUEEZE routine of the PLATON program package was utilized (see ESI $\dagger$ ).

\section{Acknowledgements}

M.F. thanks the Evonik Foundation for a Ph.D. fellowship. We thank the DFG (CL 489/2-1) and the Danish National Research Foundation (DNRF93) funded Center for Materials Crystallography (CMC) for financial support. We thank Dr Michael John for help with the NMR measurements and Dr Holm Frauendorf for the ESI measurements. 


\section{References}

1 (a) M. D. Pluth and K. N. Raymond, Chem. Soc. Rev., 2007, 36, 161; (b) S. J. Dalgarno, N. P. Power and J. L. Atwood, Coord. Chem. Rev., 2008, 252, 825; (c) D. J. Tranchemontagne, Z. Ni, M. O'Keeffe and O. M. Yaghi, Angew. Chem., Int. Ed., 2008, 47, 5136; (d) R. Chakrabarty, P. S. Mukherjee and P. J. Stang, Chem. Rev., 2011, 111, 6810; (e) T. K. Ronson, S. Zarra, S. P. Black and J. R. Nitschke, Chem. Commun., 2013, 49, 2476.

2 (a) N. Gimeno and R. Vilar, Coord. Chem. Rev., 2006, 250, 3161; (b) J. L. Sessler, P. Gale, W.-S. Cho and S. J. Rowan, Anion Receptor Chemistry (Monographs in Supramolecular Chemistry), Royal Society of Chemistry, Cambridge, 2006; (c) S. O. Kang, J. M. Llinares, V. W. Day and K. BowmanJames, Chem. Soc. Rev., 2010, 39, 3980.

3 (a) P. Mal, B. Breiner, K. Rissanen and J. R. Nitschke, Science, 2009, 324, 1697; (b) D. Fiedler, R. G. Bergman and K. N. Raymond, Angew. Chem., Int. Ed., 2006, 45, 745; (c) M. Kawano, Y. Kobayashi, T. Ozeki and M. Fujita, J. Am. Chem. Soc., 2006, 128, 6558.

4 (a) M. Yoshizawa, J. K. Klosterman and M. Fujita, Angew. Chem., Int. Ed., 2009, 48, 3418; (b) Molecular Encapsulation: Organic Reactions in Constrained Systems, ed. U. H. Brinker, J. Mieusset, Wiley, Hoboken, 2010.

5 S. Bivaud, J.-Y. Balandier, M. Chas, M. Allain, S. Goeb and M. Sallé, J. Am. Chem. Soc., 2012, 134, 11968.

6 M. Han, R. Michel, B. He, Y.-S. Chen, D. Stalke, M. John and G. H. Clever, Angew. Chem., Int. Ed., 2013, 52, 1319.

7 (a) S. Freye, J. Hey, A. Torras-Galán, D. Stalke, R. HerbstIrmer, M. John and G. H. Clever, Angew. Chem., Int. Ed., 2012, 51, 2191; (b) S. Freye, D. M. Engelhard, M. John and G. H. Clever, Chem.-Eur. J., 2013, 19, 2114; (c) J. M. Dieterich, G. H. Clever and R. A. Mata, Phys. Chem. Chem. Phys., 2012, 14, 12746.

8 M. Frank, J. M. Dieterich, S. Freye, R. A. Mata and G. H. Clever, Dalton Trans., 2013, 42, 15906.

9 S. Freye, R. Michel, D. Stalke, M. Pawliczek, H. Frauendorf and G. H. Clever, J. Am. Chem. Soc., 2013, 135, 8476.

10 M. Frank, J. Hey, I. Balcioglu, Y.-S. Chen, D. Stalke, T. Suenobu, S. Fukuzumi, H. Frauendorf and G. H. Clever, Angew. Chem., Int. Ed., 2013, 52, 10102.

11 For other examples of kinetic effects in the self-assembly of coordination cages see: (a) S. Sato, Y. Ishido and M. Fujita, J. Am. Chem. Soc., 2009, 131, 6064; (b) Y. Sakata, S. Hiraoka and M. Shionoya, Chem.-Eur. J., 2010, 16, 3318; (c) O. Chepelin, J. Ujma, P. E. Barran and P. J. Lusby, Angew. Chem., Int. Ed., 2012, 51, 4194; (d) H. Kumari, A. V. Mossine, S. R. Kline, C. L. Dennis, D. A. Fowler, S. J. Teat, C. L. Barnes, C. A. Deakyne and J. L. Atwood, Angew. Chem., Int. Ed., 2012, 51, 1452.

12 For reviews and selected examples see: (a) M. M. SafontSempere, G. Fernández and F. Würthner, Chem. Rev., 2011, 111, 5784; (b) M. Lal Saha and M. Schmittel, Org. Biomol. Chem., 2012, 10, 4651; (c) R. Krämer, J.-M. Lehn and A. Marquis-Rigault, Proc. Natl. Acad. Sci. U. S. A., 1993, 90, 5394; (d) D. L. Caulder and K. N. Raymond, Angew. Chem., Int. Ed. Engl., 1997, 36, 1440; (e) R. Pinalli, V. Cristini, V. Sottili, S. Geremia, M. Campagnolo, A. Caneschi and E. Dalcanale, J. Am. Chem. Soc., 2004, 126, 6516; (f) B. Brusilowskij, E. V. Dzyuba, R. W. Troff and C. A. Schalley, Chem. Commun., 2011, 47, 1830.

13 M. J. Frisch, G. W. Trucks, H. B. Schlegel, G. E. Scuseria, M. A. Robb, J. R. Cheeseman, G. Scalmani, V. Barone, B. Mennucci, G. A. Petersson, H. Nakatsuji, M. Caricato, X. Li, H. P. Hratchian, A. F. Izmaylov, J. Bloino, G. Zheng, J. L. Sonnenberg, M. Hada, M. Ehara, K. Toyota, R. Fukuda, J. Hasegawa, M. Ishida, T. Nakajima, Y. Honda, O. Kitao, H. Nakai, T. Vreven, J. A. Montgomery Jr., J. E. Peralta, F. Ogliaro, M. Bearpark, J. J. Heyd, E. Brothers, K. N. Kudin, V. N. Staroverov, R. Kobayashi, J. Normand, K. Raghavachari, A. Rendell, J. C. Burant, S. S. Iyengar, J. Tomasi, M. Cossi, N. Rega, J. M. Millam, M. Klene, J. E. Knox, J. B. Cross, V. Bakken, C. Adamo, J. Jaramillo, R. Gomperts, R. E. Stratmann, O. Yazyev, A. J. Austin, R. Cammi, C. Pomelli, J. W. Ochterski, R. L. Martin, K. Morokuma, V. G. Zakrzewski, G. A. Voth, P. Salvador, J. J. Dannenberg, S. Dapprich, A. D. Daniels, O. Farkas, J. B. Foresman, J. V. Ortiz, J. Cioslowski and D. J. Fox, Gaussian 09, Gaussian, Inc., Wallingford CT, 2009.

14 T. Kottke and D. Stalke, J. Appl. Crystallogr., 1993, 26, 615619.

15 Bruker SAINT v8.30C, Madison, 2013.

16 G. M. Sheldrick, SADABS 2012/1, Göttingen, 2012.

17 G. M. Sheldrick, XPREP Version 2012/1 for Windows, Göttingen, 2005.

18 G. M. Sheldrick, Acta Crystallogr., Sect. A: Found. Crystallogr., 1990, 46, 467-473.

19 G. M. Sheldrick, Acta Crystallogr., Sect. A: Found. Crystallogr., 2008, 64, 112-122.

20 C. B. Hübschle, G. M. Sheldrick and B. Dittrich, J. Appl. Crystallogr., 2011, 44, 1281-1284. 